\title{
The Angle Sum Theory: \\ Exploring the Literature on Acknowledgments in Scholarly Communication ${ }^{1}$
}

\author{
Nadine Desrochers, Adèle Paul-Hus and Vincent Larivière
}

\section{Introduction}

"The authors would like to thank" and other variations on this formulation are one of many conventions by which researchers bestow their gratitude upon the individuals, organizations, or funding agencies that help research come to fruition as published works. However, beyond niceties, these often formulaic sentences are also the markers of a clear division in academic standing: those who have obtained the status of author, as established by varying and often unclear parameters (International Committee of Medical Journal Editors, 2006; 2013; Pontille, 2004), and those who are denied such status. There are also individuals whose names appear in reference lists. References bestow yet another status upon the individuals they name - and they do so whether the referenced work is alluded to, praised, questioned, or critiqued.

Thus emerge the three statuses that have come to form the "reward triangle" (Cronin \& Weaver-Wozniak, 1993) of science: author, person cited, person thanked. Merton's (1973) work on the structure of the scientific community and, more specifically, on cumulative advantages in science (i.e., the Matthew Effect), shed light on the process by which an individual moves from being an accessory to becoming an author-and back again, although with more prestige, through the accumulation of citations or by being acknowledged for his or her contribution to a work. In this way, acknowledgments place the highly regarded alongside those who have not yet attained recognition.

Blaise Cronin began studying the dynamics of scientific acknowledgments in the 1990s, quickly placing his work among the few models in existence or in development at the time (Mackintosh, 1972; McCain, 1991; in Cronin, 1995). He revived his interest for this topic at various moments in his career and with various collaborators, creating an unrivalled body of work on acknowledgments in scholarly communication. In recent years, the relationship between

\footnotetext{
${ }^{1}$ Published as a chapter in Theories of Informetrics and Scholarly Communication (2016). Please cite : Desrochers, N., Paul-Hus, A. and Larivière, V. (2016). The angle sum theory: Exploring the literature on acknowledgments in scholarly communication. Sugimoto, C.R. (Ed.). Theories of Informetrics and Scholarly Communication. Berlin: De Gruyter Mouton, pp. 225-247.
} 
those who thank and those-individuals or organisations-who are thanked has been studied theoretically and empirically.

This chapter maps the landscape of research on scientific acknowledgments which has appeared relatively regularly in the literature since the 1970s. Analyses of the role and value of acknowledgments are often isolated by discipline or methodological approach, and present dataspecific models or adaptations of previous models as premises for new analyses. We provide here an analytical review of the literature on acknowledgments in scholarly communication in order to gauge how this phenomenon has been studied. This is not a systematic review in the methodological sense; rather, we triangulate qualitative analysis and quantitative descriptions to paint a portrait of the acknowledgement literature in terms of approaches, theories, contributions, trends, and limitations.

\section{Triangulating the Rewards of Science}

The social sciences' penchant for figures and the geometric schematization of concepts is served well by the notion of a "reward triangle." This turn of phrase represents the basic premise upon which acknowledgments research is built. In 1995, Cronin posited that, "authorship and citation do not tell the whole story," and situated acknowledgments as "another vector" in the assessment of scholarship (p. 14). Three years earlier, he had underlined the intrinsic value of certain types of acknowledgments by qualifying them as "closet citations" (Cronin, 1992, p. 25). Twenty years prior to that, however, Mackintosh had been even more categorical: "[L]ack of interest in acknowledgements does not necessarily indicate their complete irrelevance as rewards in science, or, if it does, then citations of one's published work by others must fall at the same stroke" (p. 70).

The "reward triangle" phrase itself was coined in 1993 by Cronin and Weaver-Wozniak: "If authorship and citedness are to be counted, so ought acknowledgments. By admitting acknowledgments, the Reward Triangle is closed" (p. 94). This image, reintroduced by the same authors two years later (Cronin \& Weaver, 1995; Cronin, 1995, p. 27), featured prominently in the title of a recent paper by Costas and van Leeuwen (2012) in which the authors further cite Cronin and Weaver (p. 1648), thereby revealing sustained interest in this imagery.

The perception of the fruits of scholarly pursuits as "rewards" allows for an easy stretch towards Mertonian and later Bourdieusian perspectives which have had either stated or indirect 
influences in acknowledgments literature. Acknowledgments research has long been anchored in the conceptual framework of a "reward system of science" (Mackintosh, 1972, p. 16; ${ }^{2}$ McCain, 1991, p. 495). Cronin integrated both theoretical perspectives in his corpus, at times in tandem, for example in The Hand of Science: Academic Writing and its Rewards (2005). This book offers, in itself, a framework for the study of the "reward system of science, understood in terms of an economy of attention" (p. 5). Therefore, we can argue for a triumvirate of theoreticians in the study of the reward triangle: Cronin, Bourdieu, and Merton.

Acknowledgments have a dubious reputation. This is due, first, to their "subtler" (Cronin, 1992, p. 128), and more "personal" (Hyland, 2003, p. 243) nature; second, to the fact that they are unruly, and not "as frequent or as standardized" as citations (Cronin, 2014, p. xvii); and third, to their perceived propensity to be, at least in certain cases, "self-serving gestures, [...that are] by no means innocent" (Coates, 1999, p. 255). Perhaps given these very characteristics, acknowledgments offer insight into both the scientific field and the incarnation of that field in the very person of the scientist (see Bourdieu, 2001, pp. 84-85)-the "homo academicus" (Bourdieu, 1984). The practice of acknowledgments, its forms, its purposes, and its evolution are of course deeply rooted in the scholar's habitus, and it goes without saying that the set of dispositions which form this habitus answer to both the broader field of scholarly production and disciplinary paradigms. Again because of their nature, acknowledgments participate in the illusio upon which the scientific field, like all others (Bourdieu, 1996, p. 228) is built: the premise whereby adhering to the rules of the game supposes, ipso facto, that one deems this game relevant and, more importantly, worth one's time, effort and, as is often the case for academics, livelihood. Bourdieu (1988) insists on this: without illusio, "there would be no stakes to play for, nor even any game" (p. 56). ${ }^{3}$

As stated above, acknowledgments can also testify to the ebb and flow of legitimization (often provided by authorship) and consecration (intrinsic to citation), which are key in the construction of symbolic capital - the "accumulation" of which "is a driving force of academic life" (Cronin, 2005, p. 139). Finally, acknowledgments differ from authorship or citations in that they can satisfy the two sets of values that underlie symbolic goods: the obvious symbolic values

\footnotetext{
${ }^{2}$ Mackintosh cited Merton, but not Bourdieu—likely because the first English translations of Bourdieu's works were not published until the late 1970s.

${ }^{3}$ Interestingly, the English translation omitted part of the sentence here; the original French text is more specific, since it qualifies the illusio as "an adherence to the cultural arbitrary that is the very foundation of the group" (1984, p. 80 , our translation).
} 
of contribution and intellectual indebtedness, but also the economic value, often decried, yet obviously intrinsic to all fields where funds are involved. Such is the role of funding acknowledgments or the identification of paid services, facilities, and institutions.

This chapter presents an analytical review of the literature on acknowledgments in scholarly communication, demonstrating the significance of acknowledgements in the reward system of science. In doing, so, we will show that the interactions between the three elements of the triangle (authorship-citations-acknowledgments) play a fundamental role in the illusio that shapes the sociology of science.

\section{Finding the Literature}

We searched the following bibliographic databases to retrieve items pertaining to acknowledgments in scholarly communication: Web of Science (WoS) citation indexes (Science Citation Index Expanded, Social Sciences Citation Index, Arts \& Humanities Citation Index, Conference Proceedings Citation Index-Science and Conference Proceedings Citation Index); Library and Information Sciences Abstracts (LISA); Library, Information Science \& Technology Abstracts (LISTA); Library Literature \& Information Science Index; Dissertation \& Theses (ProQuest); FRANCIS; and Sociological Abstracts. Keyword ${ }^{4}$ and controlled-vocabulary searches were used, as well as pearl-growing techniques (Bopp \& Smith, 2011, p. 112). We then examined and mined the reference lists of relevant items, which were identified through a preliminary assessment of abstracts or a summary reading. The dataset was considered "open," as new items could always be added, no matter their means of discovery. As stated, this was an exploratory analysis of the existing literature, rather than a systematic review. A total of 115 items were identified and selected for analysis.

Two researchers independently read the retrieved documents in order to ascertain the relevance of these items to acknowledgments research and to assign initial classification tags to each of them. Only one item caused a tagging conflict, which was resolved through discussion.

The following rounds of analysis were qualitative and inductive. Researchers jointly validated the original tags assigned to each document and identified 71 documents for a deeper qualitative analysis. 10 documents were excluded (this was validated by both researchers) and

\footnotetext{
${ }^{4}$ Keywords searched in title, keyword and abstract fields: acknowledgement*, acknowledgment*, author*, subauthorship OR sub-author*, credit*, contribution*, reward*, gratitude and courtes*.
} 
reasons for exclusion were: false positives, format (presentation notes or abstracts of work published elsewhere in more complete form); book reviews; documents not written in English or French; ${ }^{5}$ and documents not secured before the end of the analysis process-these items were deemed, upon evaluation of the abstracts, as having little potential impact on the findings. The remaining documents were classified as "peripheral," meaning that they informed the research in some way, but were not part of the "core" dataset.

Due to the preliminary nature of analysis, the coding that ensued was, of course, "datadriven" (Schreier, 2012, p. 88), but did not begin with a tabula rasa. Rather, it was directed by the premise emanating from the framework presented above and the aspect of the illusio it supports: that acknowledgments are worth studying. While such a stated theoretical bias is, of course, quite acceptable in directed qualitative research, it can make it "more likely" for researchers "to find evidence that is supportive rather than nonsupportive of a theory" (Hsieh \& Shannon, 2005, p. 1283). Given the fact that our stated goal was to provide the reader with a foray into the current state of the literature, we wished to target certain aspects, and so had some "predetermined" categories (Hsieh \& Shannon, 2005, p. 1282), such as the discipline of the sample (where applicable), the methods used, the presentation of a model, etc. However, aside from these broad axes, the rest of the codes emerged from the iterative readings of the texts. Nevertheless, while the overview presented here is analytical in nature, it does not have the pretension to be a full content analysis of the textual data contained in the documents that were examined.

These limitations notwithstanding, some validations and verification measures were put into place throughout the process, in a manner that befits the review approach and the methodology used, in accordance with the flexibility (White \& Marsh, 2006) and contextual principles (Morse et al., 2002) of qualitative studies. Treating the whole document as the unit of analysis, one coder (C1) used an initial subset of 10 texts to create a first codebook; the coding scheme was then used on the same 10 documents by the second coder (C2). The two coders met and discussed their respective coding. The codebook was then refined and a new version was proposed. All the coding for the original subset of 10 was imported to the revised codebook; the

\footnotetext{
${ }^{5}$ While we did not actively search for French-language texts, we did not exclude the ones that came to our attention, since we were capable of analyzing them; nevertheless, it goes without saying that studying the literature from other languages and cultures might yield other interesting findings.
} 
two coders reconciled all conflicting codes and made sure that they were in agreement regarding any coding change resulting from the revision of the codebook.

The analysis was then continued in parallel with open discussions between the two coders throughout the process and as they each coded different texts. If the creation of a new code was deemed necessary, or if a coder questioned the application of a code, the case was discussed and resolved. The creation of a new code was always accompanied by the decision to recode any texts that may be affected by this addition. As a measure of verification, after the coding of all documents was completed, $\mathrm{C} 2$ recoded 10 of C1's documents; few conflicts arose, but were resolved through discussion. During the process, memos were kept to document each step; furthermore, various notes and comments on the content of the papers were inserted in the coding spreadsheet itself. More reading led to more discoveries, and, by the end of the process, 80 items had been analysed.

Ultimately, what we propose is a classification of the body of work on acknowledgments, in the hopes that it will guide others in their own research; we encourage this namely through the lists presented in Appendix 1 which contain the full references of the documents we analyzed and which form the core dataset of 80 documents; these include: 66 journal articles, 9 book chapters, 2 books, 2 conference proceedings papers and 1 doctoral dissertation.

\section{Assessing the Trends in the Literature}

The 80 documents form a foundation for anyone aiming to research acknowledgments in scholarly communication from the "rewards of science" perspective, as represented in Figure 1.1. Of these, 59 can be considered acknowledgment-centric. This includes 11 documents that pertain to acknowledgments in theses and dissertations (T\&D), which are treated as specific types of academic output and perceived as having an acknowledgment culture of their own. 


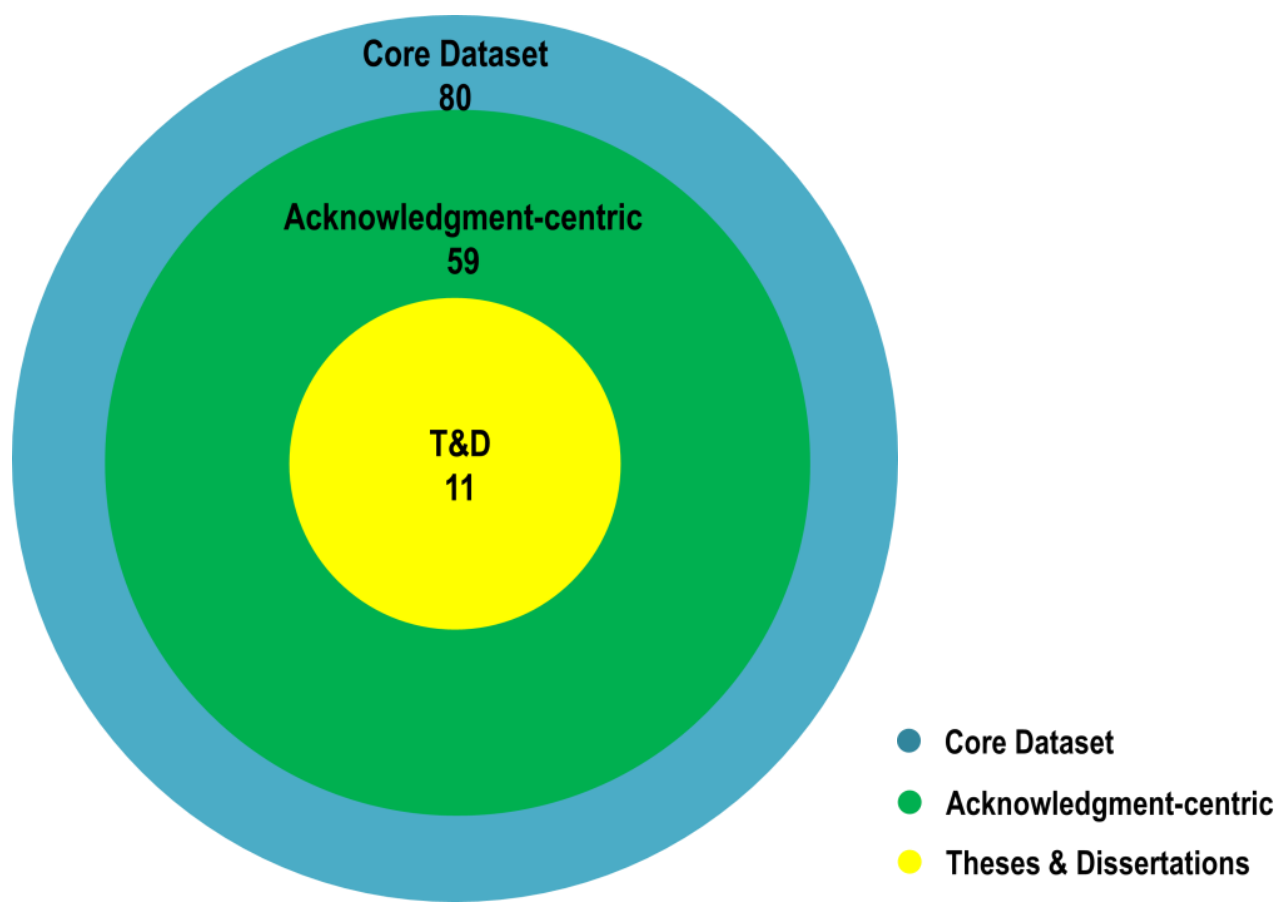

Figure 1.1. Core dataset of documents considered in the analysis

\section{Bibliometric characteristics}

As shown in Figure 1.2, the publication years of the 80 documents indicate a clear rise of the interest in the topic in the 1990s, with waxing and waning in the following decades creating a pendulum effect. 


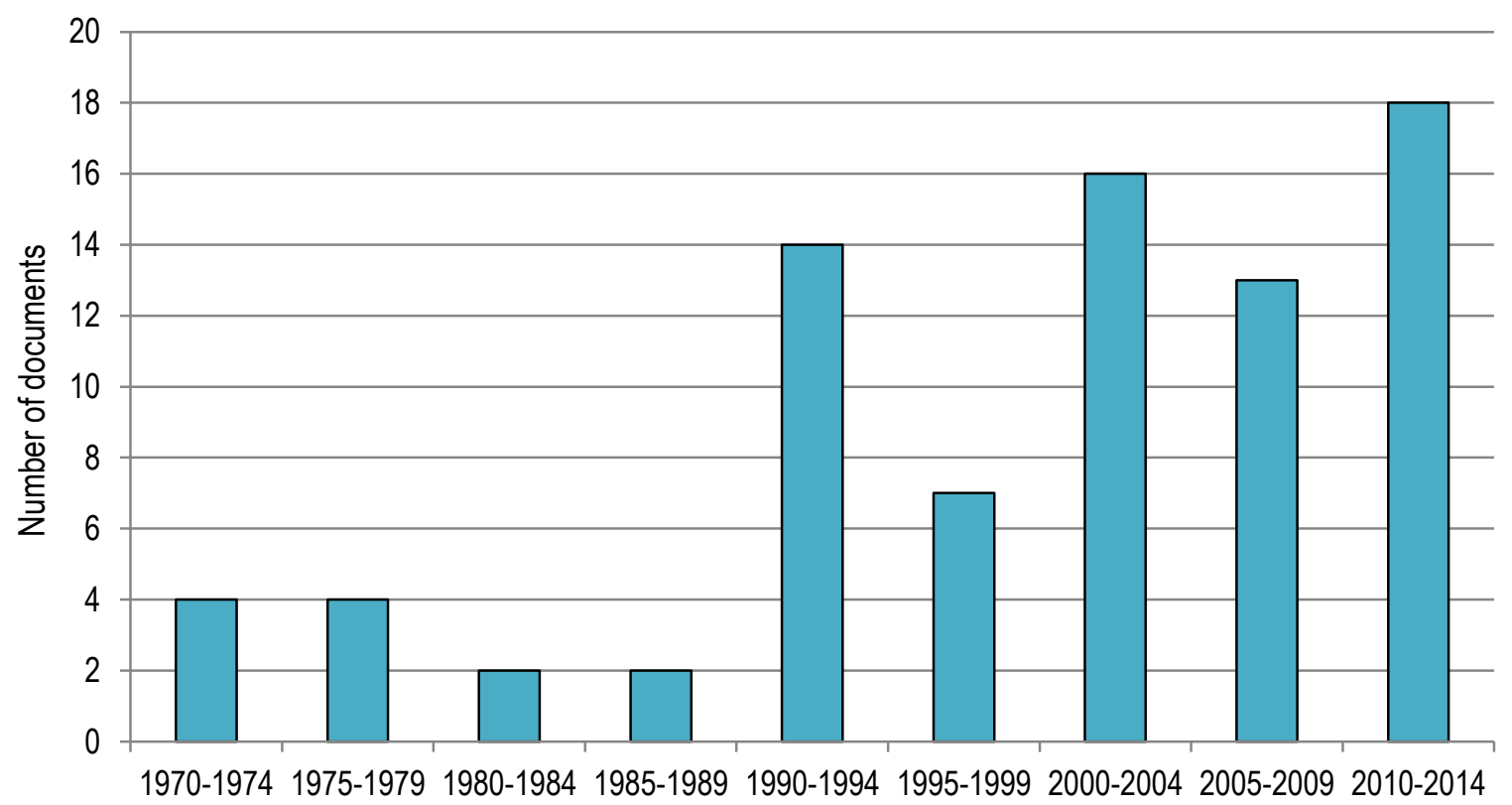

Figure 1.2. Evolution of the number of documents published on acknowledgments, 1970-2014

Table 1.1 presents the authors who contributed more than one item to the core dataset, whether as sole author or as co-authors. It clearly shows that Cronin's work is the unequivocal cornerstone of research on the topic. Some of his work builds on or presents other angles of previously published research; this pattern of iterative analysis and the important (not to mention humble) realization that "one's perspective changes over time" (Cronin, 2005, p. 15) are just some of the factors that have shaped Cronin's corpus as authoritative. ${ }^{6}$

\footnotetext{
${ }^{6}$ A bibliometric analysis could be performed, in further studies, to show the progression and influence of Cronin's acknowledgment-centric work through the years.
} 
Table 1.1. Authors of acknowledgments research corpus

\begin{tabular}{lr}
\hline Author & $\begin{array}{r}\text { Number of } \\
\text { documents }\end{array}$ \\
\hline Cronin, Blaise & 23 \\
Salager-Meyer, Françoise & 4 \\
Weaver (Wozniak), Sherrill $^{*}$ & 4 \\
Alcaraz-Ariza, María Ángeles & 3 \\
Berbesí, Maryelis Pabón & 3 \\
Giannoni, Davide Simone & 3 \\
Hyland, Ken & 3 \\
McKenzie, Gail * & 3 \\
Shaw, Debora * & 3 \\
Tiew, Wai Sin & 3 \\
Chubin, Daryl. E. & 2 \\
Costas, Rodrigo & 2 \\
Heffner, Alan. G. & 2 \\
Rubio, Lourdes * & 2 \\
Sen, B. K. & 2 \\
van Leeuwen, Thed N. & 2 \\
Verner, Dima & 2 \\
Yang, Wenhsien & 2 \\
(60 other authors) & 11 \\
\hline
\end{tabular}

* Collaborators of Cronin. To our knowledge, these authors did not contribute to acknowledgments research beyond the publications co-authored with Cronin.

Given the formats of the documents, establishing the fields that have taken an interest in acknowledgments research is slightly more complex. Limiting our analysis to the journal articles and using the Web of Science "Research Areas" classification of journals (Web of Science, 2012), we identified the field of publication of the 52 journal articles from our corpus that were indexed in WoS (where there were more than one category assigned, we favoured disciplinary categories such as "Information Science \& Library Science" over broader categories such as "Social Sciences"). To this, we added, as shown in Table 1.2, the 14 journal articles not indexed in WoS but whose journal titles or editorial mission clearly situates them in a given discipline. 
Table 1.2. Number of articles by "Research areas"

\begin{tabular}{lr}
\hline Research areas & $\begin{array}{r}\text { Number of } \\
\text { journal articles }\end{array}$ \\
\hline Information Science \& Library Science & 37 \\
Linguistics & 11 \\
History \& Philosophy of Science & 3 \\
Astronomy & 2 \\
Education & 2 \\
Literature & 2 \\
Psychology & 2 \\
Anthropology & 1 \\
Business \& Economics & 1 \\
Communication & 1 \\
Medical Ethics & 1 \\
Science \& Technology & 1 \\
Social Issues & 1 \\
Sociology & 1 \\
\hline
\end{tabular}

Granted, our search strategies may have created a bias towards Information Science and Library Science; nevertheless, we harnessed a strong output of Linguistics contributions, as well as articles from other fields. However, Tables 1.2 and 1.3 clearly show the preponderance of Information Science and Library Science (including bibliometrics) contributions to the acknowledgments research corpus.

Table 1.1. Number of articles by journal

\begin{tabular}{lr}
\hline & $\begin{array}{r}\text { Number of } \\
\text { Journal }\end{array}$ \\
\hline Journal of the Association for Information Science and Technology
\end{tabular}


${ }^{1}$ Previously known as the Journal of the American Society for Information Science and Technology and the Journal of the American Society for Information Science.

Only journals with more than one article are named.

These disciplinary boundaries may yet be seen as arbitrary and, in many respects, they are, because other systems may classify academic disciplines differently. Interestingly, the complexity that accompanies the notion of "discipline" (Abbott, 2001) allows us what we hope to be an eloquent leap into our findings, in which such boundaries certainly play an important part.

\section{Conceptual characteristics}

Let us begin by noting that our dataset contains items that do not present original empirical research but whose conceptual or theoretical contributions help shape the acknowledgments research landscape. We have already mentioned the importance of Cronin's The Hand of Science (2005). To this, we add Cronin's 1992 “Opinion” paper in the Bulletin of the American Society for Information Science, Cronin's 2012 comparison of artistic and scientific collaboration in Information \& Culture, and Cronin's foreword to the book Examining Paratextual Theory and its Applications in Digital Culture (co-edited by one of this chapter's authors; 2014).

Other texts contribute to the topic by proposing theoretical and critical views of acknowledgments as representative of the field-made-man, to revive the Bourdieusian image evoked earlier (2001, pp. 84-85). This can help contextualize the dichotomous reputation of acknowledgments as valuable tools for insight into the field and excessively self-serving academic fluff. Some authors even offer comic relief. Hollander (2002) notes, for instance, that "Never do we come upon an author who does not wholeheartedly embrace criticism" (p. 64); he even describes the self-portraits of scientific acknowledgments as "disarmingly humble, selfeffacing, even self-deprecating, sometimes bordering on confessions of incompetence" (p. 65). Such tone puts a great deal of weight on those the literature has come to call "trusted assessors" (see for example Mullins \& Mullins, 1973, pp. 21, 32; Chubin, 1975b, pp. 363, 365; Cronin, 1991; Cronin, 1995, p. 18; Cronin, 2005, p. 56). The sometimes incongruous humanity shown through the acknowledgments' looking-glass is epitomized in the fictitious want-ad derived by Corey Coates from his 1999 analysis of acknowledgments of spouses in English Studies monographs: 
WANTED: Wife for scholar. Duties: general help -- researching, proofing, typing/wordpro, indexing, style advice. Good humour and cheer necessary. Patience and endurance essential. Hours: many, variable. Remuneration in form of short acknowledgment. (pp. 258-259)

On the more serious side, reading conceptual pieces can help contextualize empirical works by providing the backdrop against which these studies were conducted. In that sense, Chubin (1975) helps contextualize early research like that of Mackintosh (1972); likewise, Caesar (1992) complements the work of McCain (1991) and the early Cronin studies.

Perspectives, of course, vary. We found that 34 of the 80 items included some analysis of the attributes of the acknowledgments themselves (length, placement, form, structure, wording, etc.) and some also performed a linguistics move-pattern analysis. In certain cases (such as AlAli, 2010 and Gesuato, 2004), acknowledgments were the central focus of a detailed text-based analysis. In other cases, like some early Cronin pieces, the discussion on style was brief, mentioned almost in passing, and used mostly as a means of outlining the importance of the actual wording in studying acknowledgments. This might be done, for example, with respect to the language used to thank certain people (Cronin, 1992b, p. 131), through a look at language trends by discipline (Cronin, McKenzie, \& Rubio, 1993, p. 41), or by mentioning the difficulties wording can create in the analysis (Cronin, McKenzie, \& Stiffler, 1992, p. 112). Another trend was research by comparison. Comparative findings by such variables as journals, researchers, disciplines, countries, types of documents, or time-period were found in 51 items (including different papers based on the same studies).

Finally, there is a clear propensity in the literature for suggesting typologies of acknowledgments. However, this is not as straightforward as might appear. We looked at this qualitatively and coded for an angle to the research that would address the questions "who gets thanked for what?," "who gets thanked instead of being an author?," or "what are the roles, functions, or statuses of the people and organizations being thanked?;" we took into consideration occurrences of typologies presented in text, whether as findings or as models. This allowed us to identify 50 documents that could be analyzed further to draw comparisons and establish potential trends in terms of how acknowledgments are constructed, why they are included in a publication, as well as any proposed typologies or models. It should be noted that this is a very heterogeneous set. In some cases, following Hyland's 2004 model, the purpose 
(such as "Thanking for academic assistance") is presented as a subcategory of a structural analysis (p. 308); Al-Ali (2010) presents an adaptation of this model (p. 8) while Yang (2012) uses it as a framework for quantitative descriptions. In Basthomi's (2008) analysis, the focus is placed on how people are thanked; yet its method yields a list of who gets thanked (p. 4) as a necessary by-product. The reporting style of the aforementioned Coates (1999) does not afford him a typology, but one could certainly be derived from a qualitative content analysis of his findings.

Of course, Cronin's typologies are presented as central frameworks in Library and Information Science; this is true of the original six-part typology (1991, p. 231), which he built before encountering Mackintosh's 1972 work and simultaneously with McCain's 1991 work (1995, p. 41). It is also true of the subsequent typologies he developed with other collaborators, namely Weaver, between 1992 and 1995. These foundational classifications are sometimes presented in a continuum with other models (e.g. Tiew \& Sen, 2002, p. 45; Rattan, 2013); they are also adapted, tweaked, or augmented, either slightly or significantly (e.g. Salager-Meyer, Alcaraz-Ariza, Berbesí, \& Zambrano, 2006; Salager-Meyer, Alcaraz-Ariza \& Berbesí, 2009; Weber \& Thomer, 2014).

\section{Limitations}

The aim of the analytical review presented in this chapter is to provide insight into the acknowledgments research literature from the reward triangle perspective. Its limitations are obvious: the research strategy had a strong LIS and social sciences bias, given the fact that the bulk of the research was done in databases which favor journals over monographs. We did try to remedy this through bibliography mining, which made the dataset both richer and more complete. Furthermore, our qualitative content analysis was exploratory and used the document as its unit of analysis.

Other avenues could be pursued, including an analysis of the papers that pertain strictly to funding acknowledgments (FA); these were excluded from our analysis since they were seen as lying outside our reward triangle paradigm. We nevertheless flag this as a fast-growing field, namely thanks to the addition in the Web of Science databases of three funding acknowledgments or FA-related fields (Web of Science, 2009). As noted above, a review of the literature in other languages would be another important addition to this landscape. 
Finally, the literature on acknowledgments in the context of editorial standards or guidelines should also be considered. As the interest for authorship and acknowledgments has been growing in the past decades, the editorial and opinion pieces that have been published since Kassirer and Angell (1991) raised the issue of the proliferation of acknowledgments in scientific articles would certainly warrant attention and add depth to the discussion.

\section{Summing Up the Reward Triangle}

We have already anchored our review in the reward triangle paradigm proposed by Cronin and Weaver-Wozniak (1993) and Cronin and Weaver (1995). The triangle figure was also used by Cronin in The Hand of Science to illustrate the aptly named "triadic sign systems" of references, acknowledgments, and citations through a semiotic lens (2005, pp. 147-151). We have chosen to expand upon this imagery.

Although none of the Cronin (1995) or Cronin and Weaver (1995; and as WeaverWozniak, 1993) articles nor the Costas and van Leeuwen (2012) article offer an actual visualization of the reward triangle, an instinctive reading might lead to something like what is presented in Figure 1.3.

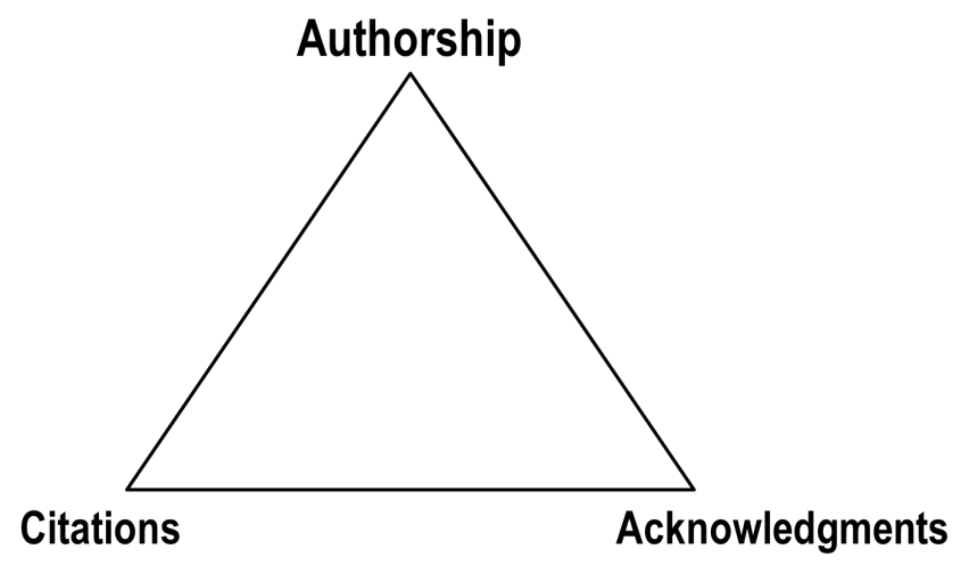

Figure 1.3. The reward triangle: A classic interpretation

However, through the help of the literature reviewed here, we now have an opportunity to visualize this triangle differently and to further its use by looking inside in more detail, all the while examining the relationships created between the three constitutive elements.

The angle sum theorem is a basic geometric paradigm: the sum of the measures of the interior angles of any given triangle is $180^{\circ}$. Building on this Euclidian truth, we propose an 
angle sum theory of the reward triangle in the scientific field. To do this, we moved the three constitutive elements from the vertices (understood here in the mathematical sense as all intersections), to the sides, as shown in Figure 1.4.

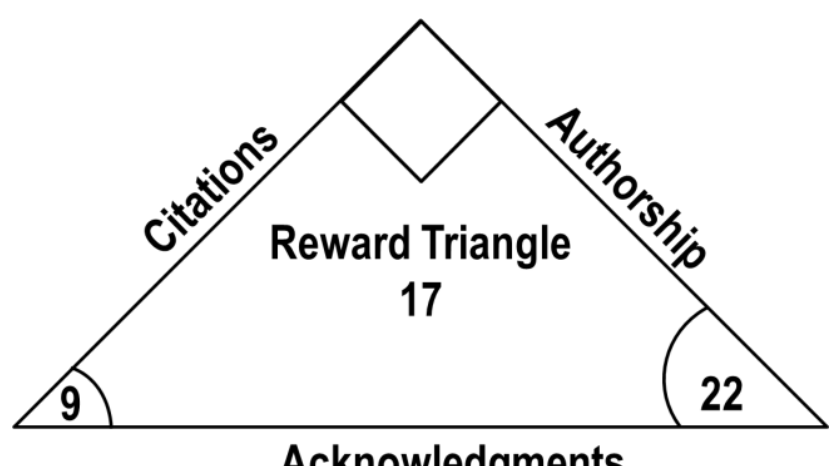

Acknowledgments

Figure 1.4. The reward triangle: An angle sum theory interpretation of the literature, with the distribution of the relevant dataset numbers

The apex of the triangle is where authorship meets citations. Scholarly performance is often assessed by both measures: "[t]o set the reward register ringing, all a scholar has to do is feature as an author or co-author and/or have his work cited by another" (Cronin \& Weaver, 1995, p.173). Indeed, if becoming an author grants legitimization, becoming a cited author grants consecration, in a field where one of the objectives, according to Bourdieu (1988) is to "make a name for oneself" (p. 2). In other words, the apex of the figure is not just authorship, but the intersection of authorship and intellectual influence - the intersection of an author's "productivity" and an author's "productive impact" (Cronin, 1995, pp. 14-15). This is the cornerstone of the scientific reward system. While the literature solely devoted to these two features was not included in our corpus, this angle has been studied thoroughly by a large body of literature and is at the core of the bibliometrics field; hence the right angle, fixed and enduring, to represent the body of research pertaining to the authorship-citation relationship.

The hypotenuse of the triangle, opposite to the right angle, represents acknowledgments. It is the broader base. It is foundational because collaboration is key to producing high-impact knowledge (Larivière et al., 2014). It is broad because acknowledgments remain, for the most part, elective textual testimonies that manifest in a myriad of ways reflective of the myriad contents, forms, and even purposes they espouse. 
While the right angle illustrates the strongest connection, the angle at the intersection of acknowledgments and citations constitutes the least studied portion of the triangle, with only 8 documents in our corpus addressing this relationship without much, if any, attention to authorship issues. The connection between acknowledgments and authorship has been the subject of a broader subset - our dataset includes 22 documents that discuss these two issues conjointly, with only a contextual, if any, reference to citations. Finally, the full reward triangle formed by authorship, citations, and acknowledgments was addressed in 17 documents.

In other words, to truly understand how the scientific community views and apprehends the reward triangle as both a set of independent elements and a set of relationships, one has to look not only at the centre of the figure, but also at the angles that reflect the attention given to the various relationships between the three constitutive elements. When considered along with the literature that focuses on only one of the three elements of the reward triangle, this will provide an even more complete view; it will also reveal where imbalances lie. This, in itself, is telling in terms of the values granted to each relationship as a vector of symbolic capital in the scientific field.

\section{Conclusion and Outlook}

The findings presented herein show that acknowledgments research is not an emerging field, even though it is as eclectic as acknowledgments themselves. Flattening this landscape too quickly would be reductive to the collective knowledge it has contributed to the study of the reward system of science. The scientific field, with its "high degree of codification of entry into the game," (Bourdieu, 1996, p. 226) ensures the legitimization of its members; their consecration, however, is ruled by aspects of the illusio that the sociology of science has labelled recognition after Merton (1973), capital after Bourdieu, or the reward triangle after Cronin. There are other views, of course, but these are the ones that led us to sum up, quite literally, the literature on acknowledgments research. Acknowledgments, like authorship and citations, testify to the fact that "[w]riting, in short, does not take place in a sociocognitive vacuum" (Cronin, 2005, p. 109). We now partake in more of the illusio by ending this co-authored chapter with acknowledgments and references of our own. In so doing, we are drawing the reward triangle, for ourselves and for other players in the game, from apex to hypothenuse, with every angle inbetween. 


\section{Acknowledgments}

The authors acknowledge the support of the Social Sciences and Humanities Research Council of Canada (Insight Development grants).

\section{Cited References}

Abbott, A. D. (2001). Chaos of disciplines. Chicago, IL: University of Chicago Press.

Al-Ali, M. N. (2010). Generic patterns and socio-cultural resources in acknowledgements accompanying arabic Ph.D. dissertations. Pragmatics, 20(1), 1-26.

Basthomi, Y. (2008). Interlanguage discourse of thesis acknowledgements section: Examining the terms of address. Philippine Journal of Linguistics, 39(1), 55-66.

Bopp, R. E., \& Smith, L. C. (2011). Reference and information services: an introduction. Santa Barbara, CA: Libraries Unlimited.

Bourdieu, P. (1984). Homo academicus. Paris: Les Éditions de Minuit.

Bourdieu, P. (1988). Homo academicus. Stanford, CA: Stanford University Press.

Bourdieu, P. (1996). The rules of art: Genesis and structure of the literary field. Stanford, CA: Stanford University Press.

Bourdieu, P. (2001). Science de la science et réflexivité. Paris : Éditions Raisons d'agir.

Caesar, T. (1992). On Acknowledgements. New Orleans Review, 19(1), 85-94.

Chubin, D. E. (1975). Trusted assessorship in science: A relation in need of data. Social Studies of Science, 5(3), 362-367. doi:10.1177/030631277500500307

Coates, C. (1999). Interpreting academic acknowledgements in English studies: Professors, their partners, and peers. English Studies in Canada, 25(3-4), 253-276.

Costas, R., \& van Leeuwen, T. N. (2012). Approaching the "reward triangle": General analysis of the presence of funding acknowledgments and " peer interactive communication" in scientific publications. Journal of the American Society for Information Science and Technology, 63(8), 1647-1661.

Cronin, B. (1991). Let the credits roll: A preliminary examination of the role played by mentors and trusted assessors in disciplinary formation. Journal of Documentation, 47(3), 227-239. doi:10.1108/eb026878 
Cronin, B. (1992a). Acknowledged but ignored: Credit where credit's due. Bulletin of the American Society for Information Science, 18(3) 25.

Cronin, B. (1992b). The hidden influencers: An examination of the role played by mentors and trusted assessors in the evolution of information science. In P. Vakkari \& B. Cronin (Ed.), Conceptions of library and information science : Historical, empirical and theoretical perspectives. (p. 126-134). London: Taylor Graham.

Cronin, B. (1995). The scholar's courtesy: The role of acknowledgement in the primary communication process. London: Taylor Graham.

Cronin, B. (2005). The hand of science: Academic writing and its rewards. Lanham, MD: Scarecrow Press.

Cronin, B. (2012). Collaboration in Art and in Science: Approaches to attribution, authorship, and acknowledgment. Information \& Culture, 47(1), 18-37.

Cronin, B. (2014). Foreword: The penumbral world of the paratext. In N. Desrochers \& D. Apollon (Eds.), Examining paratextual theory and its applications in digital culture. Hershey, PA: IGI Global. Retrieved February 5, 2015, from http://www.igiglobal.com/pdf.aspx?tid=122526\&ptid=97342\&ctid=15\&t=foreword

Cronin, B., \& Weaver, S. (1995). The praxis of acknowledgement: from bibliometrics to influmetrics. Revista española de documentación científica, 18(2), 172-177.

Cronin, B., \& Weaver-Wozniak, S. (1992). An online acknowledgment index: Rationale and feasibility. In D. Raitt (Ed.), Online Information 92: Proceedings of the 16th International Online Information Meeting, London, S-10 December 1992 (p. 281-290). Oxford: Learned Information.

Cronin, B., \& Weaver-Wozniak, S. (1993). Online access to acknowledgements. In Williams, M.E. (Ed.), Proceedings of the 14th National Online Meeting 1993 (p. 93-98). Medford, NJ : Learned Information.

Gesuato, S. (2004). Acknowledgments in PhD dissertations: The complexity of thanking. In C. Taylor Torsello, M. Grazia Bùsa, \& S. Gesuato (Eds.), Lingua inglese e mediazione linguistica. Ricerca e didattica con supporto telematico (p. 273-318). Padova: Unipress.

Hollander, P. (2001). Acknowledgments: An academic ritual. Academic Questions, 15(1), 63-76. doi:10.1007/s12129-001-1056-X 
Hsieh, H. F., \& Shannon, S. E. (2005). Three approaches to qualitative content analysis. Qualitative Health Research, 15(9), 1277-1288. doi:10.1177/1049732305276687

Hyland, K. (2003). Dissertation acknowledgements: The anatomy of a Cinderella genre. Written Communication, 20(3), 242-268. doi:10.1177/0741088303257276

Hyland, K. (2004). Graduates' gratitude: The generic structure of dissertation acknowledgements. English for Specific Purposes, 23(3), 303-324. doi:10.1016/S08894906(03)00051-6

International Committee of Medical Journal Editors. (2006). Uniform requirements for manuscripts submitted to biomedical journals. Retrieved on August 1, 2014, from http://www.ncbi.nlm.nih.gov/pmc/articles/PMC3142758/

International Committee of Medical Journal Editors. (2013). Recommendations. Retrieved on August 1, 2014, from http://www.icmje.org/recommendations/

Kassirer, J. P., \& Angell, M. (1991). On authorship and acknowledgments. The New England Journal of Medicine, 325(21), 1510-2. doi:10.1056/NEJM199111213252112

Larivière, V., Sugimoto, C. R., Tsou, A., \& Gingras, Y. (2014). Team size matters: Collaboration and scientific impact since 1900. Journal of the American Society for Information Science and Technology.

Mackintosh, S. H. (1972). Acknowledgment patterns in sociology (Doctoral dissertation). Retrieved from ProQuest Dissertations and Theses (Accession Order No. 7228159).

McCain, K. W. (1991). Communication, competition, and secrecy: The production and dissemination of research-related information in genetics. Science, Technology \& Human Values, 16(4), 491-516. doi:10.1177/016224399101600404

Merton, R. K. (1973). The sociology of science: Theoretical and empirical investigations. Chicago, IL: Chicago University Press.

Moore, R. (2004). Cultural capital: Objective probability and the cultural arbitrary. British Journal of Sociology of Education, 25(4), 445-456. doi:10.1080/0142569042000236943

Morse, J. M., Barrett, M., Mayan, M., Olson, K., \& Spiers, J. (2008). Verification strategies for establishing reliability and validity in qualitative research. International Journal of Qualitative Methods, 1(2), 13-22.

Mullins, N. C., \& Mullins, C. J. (1973). Theories and theory groups in contemporary American sociology. New York, NY : Harper and Row. 
Pontille, D. (2004). La signature scientifique: Une sociologie pragmatique de l'attribution. Paris: CNRS Éditions.

Rattan, G. K. M. (2013). Acknowledgement patterns in Annals of Library and Information Studies 1999-2012. Library Philosophy and Practice, e-journal (Paper 989). Retrieved on August 1, 2014 from http://digitalcommons.unl.edu/libphilprac/989/

Salager-Meyer, F., Alcaraz-Ariza, M. Á., \& Berbesí, M. P. (2009). "Backstage solidarity" in Spanish- and English-written medical research papers: Publication context and the acknowledgment paratext. Journal of the American Society for Information Science and Technology, 60(2), 307-317. doi:10.1002/asi.20981

Salager-Meyer, F., Alcaraz-Ariza, M. Á., Berbesí, M. P., \& Zambrano, N. (2006). Paying one's intellectual debt: Acknowledgments in conventional vs. complementary/alternative medical research. In M. Gotti \& F. Salager-Meyer (Eds.), Advances in Medical Discourse Analysis: Oral and Written Contexts (p. 407-430). Bern: Peter Lang.

Schreier, M. (2012). Qualitative content analysis in practice. London; Thousand Oaks, CA: Sage Publications.

Tiew, W. S., \& Sen, B. K. (2002). Acknowledgement patterns in research articles: A bibliometric study based on Journal of Natural Rubber Research 1986-1997. Malaysian Journal of Library \& Information Science, 7(1), 43-56.

Weber, N., \& Thomer, A. (2014). Paratexts and documentary practices: Text mining authorship and acknowledgment from a bioinformatics corpus. In N. Desrochers \& D. Apollon (Ed.), Examining paratextual theory and its applications in digital culture. Hershey, PA: IGI Global. Retrieved February 5, 2014, from http://www.igi-global.com/book/examiningparatextual-theory-its-applications/97342

Web of Science. (2009). Funding Acknowledgements. Retrieved August 3, 2014 from http://wokinfo.com/products_tools/multidisciplinary/webofscience/fundingsearch/ Web of Science. (2012). Web of Science Help: Research Areas. Retrieved August 3, 2014 from http://wokinfo.com/products_tools/multidisciplinary/webofscience/fundingsearch/

White, M. D., \& Marsh, E. E. (2006). Content analysis: A flexible methodology. Library Trends, 55(1), 22-45. doi:10.1353/lib.2006.0053 
Yang, W. (2012). A genre analysis of PhD dissertation acknowledgements across disciplinary variations. LSP Journal - Language for special purposes, professional communication, knowledge management and cognition, 3(2), 51-70.

\section{Appendix 1}

Core Dataset

\section{Acknowledgments and Co-authorship Literature (22)}

Bing, J., \& Ruhl, C. (2008). It's all my fault! The pragmatics of responsibility statements. Journal of Pragmatics, 40(3), 537-558. doi:10.1016/j.pragma.2007.04.010

Birnholtz, J. P. (2006). What does it mean to be an author? The intersection of credit, contribution, and collaboration in science. Journal of the American Society for Information Science and Technology, 57(13), 1758-1770. doi:10.1002/asi.20380

Chubin, D. E. (1975). Trusted Assessorship in science: A relation in need of data. Social Studies of Science, 5(3), 362-367. doi:10.1177/030631277500500307

Cronin, B. (2001). Hyperauthorship: A postmodern perversion or evidence of a structural shift in scholarly communication practices? Journal of the American Society for Information Science and Technology, 52(7), 558-569. http://doi.org/10.1002/asi.1097

Cronin, B., \& Franks, S. (2006). Trading cultures: Resource mobilization and service rendering in the life sciences as revealed in the journal article's paratext. Journal of the American Society for Information Science and Technology, 57(14), 1909-1918. doi:10.1002/asi.20407

Cronin, B., Martinson, A., \& Davenport, E. (1997). Women's studies: Bibliometric and content analysis of the formative years. Journal of Documentation, 53(2), 123-138. doi:10.1108/EUM0000000007196

Cronin, B., Shaw, D., \& La Barre, K. (2003). A cast of thousands: Coauthorship and subauthorship collaboration in the 20th century as manifested in the scholarly journal literature of psychology and philosophy. Journal of the American Society for Information Science and Technology, 54(9), 855-871. 
Díaz-Faes, A. A., \& Bordons, M. (2014). Acknowledgments in scientific publications: Presence in Spanish science and text patterns across disciplines. Journal of the Association for Information Science and Technology. doi:10.1002/asi.23081

Hartley, J. (2003). Single authors are not alone: Colleagues often help. Journal of Scholarly Publishing, 34(2), 108-113.

Heffner, A. G. (1979). Authorship recognition of subordinates in collaborative research. Social Studies of Science, 9(3), 377-384. doi:10.1177/030631277900900305

Heffner, A. G. (1981). Funded research, multiple authorship, and subauthorship collaboration in four disciplines. Scientometrics, 3(1), 5-12. doi:10.1007/BF02021860

Laudel, G. (2002). What do we measure by co-authorships? Research Evaluation, 11(1), 3-15. doi:10.3152/147154402781776961

Mackintosh, S. H. (1972). Acknowledgment patterns in sociology (Doctoral dissertation). Retrieved from ProQuest Dissertations and Theses (Accession Order No. 7228159).

Patel, N. (1973). Collaboration in the professional growth of American sociology. Social Science Information, 12(6), 77-92.

Pontille, D. (2001). L'auteur scientifique en question: Pratiques en psychologie et en sciences biomédicales. Social Science Information, 40(3), 433-453. doi:10.1177/053901801040003004

Salager-Meyer, F., Alcaraz-Ariza, M. Á., \& Berbesí, M. P. (2009). “Backstage solidarity” in Spanish- and English-written medical research papers: Publication context and the acknowledgment paratext. Journal of the American Society for Information Science and Technology, 60(2), 307-317. doi:10.1002/asi.20981

Salager-Meyer, F., Alcaraz-Ariza, M. Á., Berbesí, M. P., \& Zambrano, N. (2006). Paying one’s intellectual debt: Acknowledgments in conventional vs. complementary/alternative medical research. In M. Gotti \& F. Salager-Meyer (Eds.), Advances in Medical Discourse Analysis: Oral and Written Contexts (p. 407-430). Bern: Peter Lang.

Seeman, J. I., \& House, M. C. (2010). Influences on authorship issues: An evaluation of giving credit. Accountability in research, 17(3), 146-169. doi:10.1080/08989621003791986

Spiegel, D., \& Keith-Spiegel, P. (1970). Assignment of publication credits: Ethics and practices of psychologists. American Psychologist, 25(8), 738-747. doi:10.1037/h0029769 
Sugimoto, C. R., \& Cronin, B. (2012). Biobibliometric profiling: An examination of multifaceted approaches to scholarship. Journal of the American Society for Information Science and Technology, 63(3), 450-468. doi:10.1002/asi.21695

Suls, J., \& Fletcher, B. (1983). Social comparison in the social and physical sciences: An archival study. Jounal of Personality and Social Psychology, 44(3), 575-580.

Weber, N., \& Thomer, A. (2014). Paratexts and documentary practices: Text mining authorship and acknowledgment from a bioinformatics corpus. In N. Desrochers \& D. Apollon (Eds.), Examining paratextual theory and its applications in digital culture. Hershey, PA:

IGI Global. Retrieved February 5, 2014, from http://www.igi-

global.com/book/examining-paratextual-theory-its-applications/97342

\section{Acknowledgments and Citations Literature (9)}

Cronin, B. (1992a). Acknowledged but ignored: Credit where credit's due. Bulletin of the American Society for Information Science, 18(3), 25.

Cronin, B. (1992b). The hidden influencers: An examination of the role played by mentors and trusted assessors in the evolution of information science. In P. Vakkari \& B. Cronin (Eds.), Conceptions of library and information science : historical, empirical and theoretical perspectives. (p. 126-134). London: Taylor Graham.

Cronin, B. (1995). The scholar's courtesy: The role of acknowledgement in the primary communication process. London: Taylor Graham.

Cronin, B. (2001).

Cronin, B. (2014). Foreword: The penumbral world of the paratext. In N. Desrochers \& D. Apollon (Eds.), Examining paratextual theory and its applications in digital culture. Hershey, PA: IGI Global. Retrieved February 5, 2015, from http://www.igiglobal.com/pdf.aspx?tid=122526\&ptid=97342\&ctid=15\&t=foreword

Cronin, B., McKenzie, G., Rubio, L., \& Weaver-Wozniak, S. (1993). Accounting for influence: Acknowledgments in contemporary sociology. Journal of the American Society for Information Science, 44(7), 406-412.

Cronin, B., McKenzie, G., \& Stiffler, M. (1992). Patterns of acknowledgement. Journal of Documentation, 48(2), 107-122. 
Giles, C. L., \& Councill, I. G.(2004). Who gets acknowledged: Measuring scientific contributions through automatic acknowledgment indexing. Proceedings of the National Academy of Sciences of the United States of America, 101(51), 17599-17604. doi:10.2307/3374014

McCain, K. W. (1991). Communication, competition, and secrecy: The production and dissemination of research-related information in Genetics. Science, Technology \& Human Values, 16(4), 491-516. doi:10.1177/016224399101600404

Weigert, A. J. (1970). The immoral rhetoric of scientific sociology. The American Sociologist, 5(2), 111-119.

\section{Reward Triangle Literature (17)}

Bazerman, C. (1988). Theoretical integration in experimental reports in twentieth-century physics: Spectroscopic articles in Physical Review, 1893-1980. In Shaping written knowledge: The genre and activity of the experimental article in science (p. 153-186). Madison, WI : University of Wisconsin Press.

Costas, R., \& van Leeuwen, T. N. (2012). Approaching the « reward triangle »: General analysis of the presence of funding acknowledgments and «peer interactive communication » in scientific publications. Journal of the American Society for Information Science and Technology, 63(8), 1647-1661.

Cronin, B. (1991). Let the credits roll: A preliminary examination of the role played by mentors and trusted assessors in disciplinary formation. Journal of Documentation, 47(3), 227-239. doi:10.1108/eb026878

Cronin, B. (2005). The hand of science: Academic writing and its rewards. Lanham, MD.: Scarecrow Press.

Cronin, B. (2012). Collaboration in art and in science: Approaches to attribution, authorship, and acknowledgment. Information \& Culture, 47(1), 18-37.

Cronin, B., \& Overfelt, K. (1994). The scholar's courtesy: A survey of acknowledgement behaviour. Journal of Documentation, 50(3), 165-196. doi:10.1108/eb026929

Cronin, B., \& Shaw, D. (2007). Peers and spheres of influence: Situating Rob Kling. The Information Society, 23(4), 221-233. doi:10.1080/01972240701444147 
Cronin, B., Shaw, D., \& Barre, K. L. (2004). Visible, less visible, and invisible work: Patterns of collaboration in 20th century chemistry. Journal of the American Society for Information Science and Technology, 55(2), 160-168. doi:10.1002/asi.10353

Cronin, B., \& Weaver, S. (1995). The praxis of acknowledgement: From bibliometrics to influmetrics. Revista española de documentación científica, 18(2), 172-177.

Cronin, B., \& Weaver-Wozniak, S. (1992). An online acknowledgment index: Rationale and feasibility. In D. Raitt (Ed.), Online Information 92: Proceedings of the 16th International Online Information Meeting, London, S-10 December 1992 (p. 281-290). Oxford: Learned Information.

Cronin, B., \& Weaver-Wozniak, S. (1993). Online access to acknowledgements. In Williams, M.E. (Ed.), Proceedings of the 14th National Online Meeting 1993 (p. 93-98). Medford, NJ : Learned Information.

Giannoni, D. S. (1998). The genre of journal acknowledgments: Findings of a cross-disciplinary investigation. Linguistica e Filología, 6, 61-84.

Giannoni, D. S. (2002). Worlds of gratitude: A contrastive study of acknowledgement texts in English and Italian research articles. Applied Linguistics, 23(1), 1-31. doi:10.1093/applin/23.1.1

Laband, D. N., \& Tollison, R. D. (2000). Intellectual collaboration. Journal of Political Economy, 108(3), 632-662. doi:10.1086/262132

Roa-Atkinson, A., \& Velho, L. (2005). Interactions in knowledge production: A comparative case study of immunology research groups in Colombia and Brazil. Aslib Proceedings, 57(3), 200-216. doi:10.1108/00012530510599172

Tiew, W. S. (1998a). Journal of Malaysian Branch of the Royal Asiatic Society (JMBRAS) 1987-1996: A ten-year bibliometric analysis. Malaysian Journal of Library \& Information Science, 3(2), 49-66.

Tiew, W. S. (1998b). Journal of Natural Rubber Research 1987-1996: A ten-year bibliometric study. IASLIC Bulletin, 43(2), 49-57.

Other (32) 
Al-Ali, M. N. (2010). Generic patterns and socio-cultural resources in acknowledgements accompanying Arabic Ph.D. dissertations. Pragmatics, 20(1), 1-26.

Basthomi, Y. (2008). Interlanguage discourse of thesis acknowledgements section: Examining the terms of address. Philippine Journal of Linguistics, 39(1), 55-66.

Ben-Ari, E. (1987). On acknowledgments in ethnographies. Journal of Anthropological Research, 43(1), 63-84.

Brown, R. (2009). How scholars credit editors in their acknowledgements. Journal of Scholarly Publishing, 40(4), 384-398. doi:10.3138/jsp.40.4.384

Caesar, T. (1992). On acknowledgements. New Orleans Review, 19(1), 85-94.

Cheng, S. W. (2012). A contrastive study of Master thesis acknowledgements by Taiwanese and North American students. Open Journal of Modern Linguistics, 2(1), 8-17. doi:10.4236/ojml.2012.21002

Chubin, D. E. (1975). The journal as a primary data source in the sociology of science : With some observations from sociology. Social Science Information, 14(1), 157-168. doi:10.1177/053901847501400114

Coates, C. (1999). Interpreting academic acknowledgements in English studies: Professors, their partners, and peers. English Studies in Canada, 25(3-4), 253-276.

Costas, R., \& van Leeuwen, T.N. (2012). New indicators based on the 'Funding Acknowledgement' information in the Web of Science: Analysis of the effect of peer review over the impact of scientific journals. In É. Archambault, Y. Gingras, \& V. Larivière (Eds.), Proceedings of 17th International Conference on Science and Technology Indicators (p. 193-205). Montréal: Science-Metrix and OST.

Cronin, B. (2001). Acknowledgement trends in the research literature of information science. Journal of Documentation, 57(3), 427-433.

Cronin, B., McKenzie, G., \& Rubio, L. (1993). The norms of acknowledgement in four social sciences disciplines. Journal of Documentation, 49(1), 29-43. doi:10.1108/eb026909

Davis, C. H., \& Cronin, B. (1993). Acknowledgments and intellectual indebtedness: A bibliometric conjecture. Journal of the American Society for Information Science, 44(10), 590-592. doi:10.1002/(SICI)1097-4571(199312)44:10<590::AID-ASI5>3.0.CO;2-U 
Gesuato, S. (2004). Acknowledgments in PhD dissertations: The complexity of thanking. In C.Taylor Torsello, M. Grazia Bùsa and S. Gesuato (Eds.), Lingua inglese e mediazione linguistica. Ricerca e didattica con supporto telematico (p. 273-318). Padova: Unipress.

Giannoni, D. S. (2006a). Book acknowledgements across disciplines and texts. In K. Hyland \& M. Bondi (Eds.), Academic discourse across disciplines (p. 151-176). Bern: Peter Lang.

Giannoni, D. S. (2006b). Evidence of generic tension in academic book acknowledgements. In V. K. Bhatia \& M. Gotti (Eds.), Explorations in specialized genres (p.21-42). Bern: Peter Lang.

Hollander, P. (2001). Acknowledgments: An academic ritual. Academic Questions, 15(1), 63-76. doi:10.1007/s12129-001-1056-x

Hyland, K. (2003). Dissertation acknowledgements: The anatomy of a Cinderella genre. Written Communication, 20(3), 242-268. doi:10.1177/0741088303257276

Hyland, K. (2004). Graduates' gratitude: the generic structure of dissertation acknowledgements. English for Specific Purposes, 23(3), 303-324. doi:10.1016/S0889-4906(03)00051-6

Hyland, K., \& Tse, P. (2004). «I would like to thank my supervisor ». Acknowledgements in graduate dissertations. International Journal of Applied Linguistics, 14(2), 259-275. doi:10.1111/j.1473-4192.2004.00062.x

Koley, S., \& Sen, B. K. (2013). Acknowledgements in research papers in electronics and related fields: 2008-2012. SRELS Journal of Information Management, 50(5), 619-627.

Lasaky, F. G. (2011). A contrastive study of generic organization of doctoral dissertation acknowledgements written by native and non-native (Iranian) students in applied linguistics. The Modern Journal of Applied Linguistics, 3(2), 175-199.

Rattan, G. K. M. (2013). Acknowledgement patterns in Annals of Library and Information Studies 1999-2012. Library Philosophy and Practice, e-journal (Paper 989). Retrieved on August 1, 2014 from http://digitalcommons.unl.edu/libphilprac/989/

Salager-Meyer, F., Alcaraz-Ariza, M. Á., \& Berbesí, M. P. (2010). Hidden influencers and the scholarly enterprise: a cross-linguistic/cultural analysis of acknowledgments in medical research papers. In M. F. Ruiz-Garrido, J. C. Palmer-Silveira, \& I. Fortanet-Gomez (Eds.), English for Professional and Academic Purposes. Castellón, Spain: Universitat Jaume I. 
Salager-Meyer, F., Alcaraz-Ariza, M. Á., Luzardo Briceño, M., \& Jabbour, G. (2011). Scholarly gratitude in five geographical contexts: A diachronic and cross-generic approach of the acknowledgment paratext in medical discourse (1950-2010). Scientometrics, 86(3), 763-784. doi:10.1007/s11192-010-0329-y

Scrivener, L. (2009). An exploratory analysis of History students' dissertation acknowledgments. The Journal of Academic Librarianship, 35(3), 241-251. doi:10.1016/j.acalib.2009.03.004

Tiew, W. S., \& Sen, B. K. (2002). Acknowledgement patterns in research articles: A bibliometric study based on Journal of Natural Rubber Research 1986-1997. Malaysian Journal of Library \& Information Science, 7(1), 43-56.

Tokdemir Demirel, E., \& Shahriari Ahmadi, H. (2013). Lexical bundles in research article acknowledgments: A corpus comparison. Hacettepe Universitesi Egitim Fakultesi Dergisi-Hacettepe University Journal of, 28(2), 457-468.

Verner, D. (1992). Astronomy acknowledgement index 1991. The Messenger, 67, 61-62.

Verner, D. (1993). Astronomy acknowledgement index 1992. The Messenger, 71, 59.

Woolf, P. (1975). The second messenger: Informal communication in Cyclic AMP research. Minerva, 13(3), 349-373.

Yang, W. (2012a). A genre analysis of PhD dissertation acknowledgements across disciplinary variations. LSP Journal - Language for special purposes, professional communication, knowledge management and cognition, 3(2), 51-70.

Yang, W. (2012b). Comparison of gratitude across context variations: A generic analysis of dissertation acknowledgements written by Taiwanese authors in EFL and ESL contexts. International Journal of Applied Linguistics \& English Literature, 1(5), 130-146. 